\title{
A face do cinema no tecido urbano em "Os cinemas de Lisboa - um fenómeno urbano do século XX"
}

Carolina Amaral ${ }^{1}$

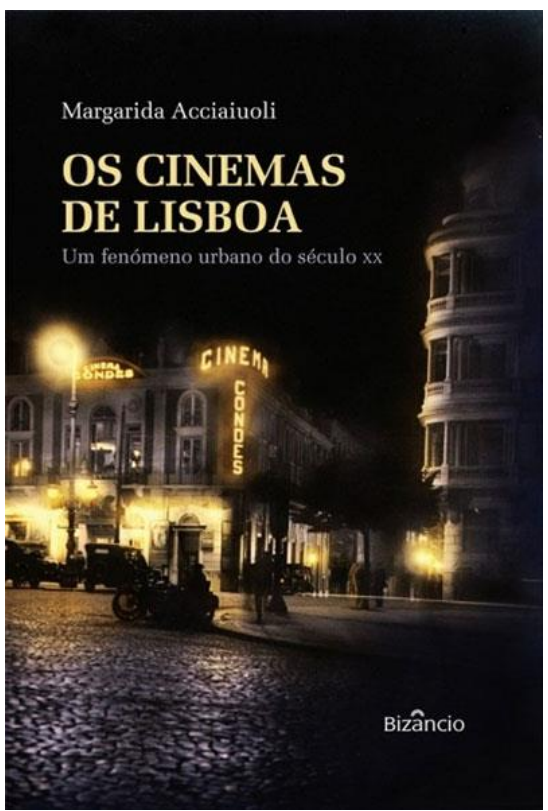

\section{Resenha}

ACCIAIUOLI, Margarida. Os cinemas de Lisboa - um fenómeno urbano do século XX. Lisboa: Bizâncio, 2012.

${ }^{1}$ Carolina Amaral é atualmente doutoranda em Comunicação Social pelo PPGCOM-UFF, linha de pesquisa estudos de cinema e audiovisual. Roteirista e pesquisadora que atua no campo de Roteiro, Narrativa e Cinema de Gênero, fez mestrado em Comunicação pela Universidade Federal Fluminense (UFF) e graduação em Comunicação Social - Cinema também na UFF. Trabalhou nas áreas de produção, direção e desenvolvimento de projetos audiovisuais. 
Os grandes cinemas de rua com imponentes fachadas não são apenas lugares em que se exibem filmes, mas locais onde se definem o espetáculo e os hábitos gerados a partir dele. $\mathrm{O}$ que, por sua vez, passa a determinar a identidade da cidade. Essas mesmas edificações assumem referências decorativas e espaciais, numa relação contínua entre o cinema e o espaço urbano. Esse é o tema do livro Os cinemas de Lisboa - um fenómeno urbano do século $X X^{2}$, de Margarida Acciaiuoli. A autora se preocupa constantemente com as relações entre a arquitetura e os cinemas de Lisboa, agenciadas por uma monumental pesquisa histórica que vai da lanterna mágica aos multiplex em centros comerciais. Sala a sala, nada escapa à costura feita pela autora, do projeto até o desaparecimento do cinema, já que quase todas as salas de cinema da cidade foram demolidas, abandonadas ou ganharam outra função.

Com excelente prefácio de João Mario Grilo, o livro se constitui de seis capítulos, que cobrem assuntos separados cronologicamente, desde 0 fim do século XIX no primeiro capítulo, até o início do século XXI no último. A intenção de dar conta da história dos cinemas na cidade vem acompanhada de uma pesquisa rica em detalhes, com abundantes citações da imprensa da época e fotografias dos espaços que hoje não existem mais.

Por se tratar de uma pesquisa acadêmica de 1982, revisitada a partir do rumo que a história dos cinemas acabou por tomar, o livro, por vezes, se concentra exaustivamente nos detalhes a cerca da arquitetura: nome do arquiteto que projetou, o empresário que encomendou, datas de licenças, detalhes de foyers e toilettes. Para os leitores cujos interesses não passam necessariamente pela arquitetura, ou para aqueles que desconhecem as salas e a cidade de Lisboa, esse volume de informação pode ser entendido como um excesso. Para evitar que esse excesso cause um afastamento da leitura, é preciso entender o funcionamento o texto e procurar, nas mais de 300 páginas, suas principais passagens, como um transeunte que se detém, seduzido por alguma majestosa fachada.

\footnotetext{
${ }^{2}$ Todas as passagens citadas remetem a este livro.
} 
O primeiro capítulo trata da reconvenção de espaços como circos, teatros e feiras em locais para exibição do animatógrafo. Segundo a autora, Lisboa compreende o cinema e se admira com ele, desde quando era uma nova "atracção" nômade. Esses primeiros espaços que acolheram a "última maravilha da técnica" levam a importância de definirem a maleabilidade dos locais de exibição com apresentações de circo, teatro, praça de touros, característica incorporada pelo cineteatro, modelo que se estabeleceu quando o cinema sedentarizou. Para a autora, é a origem nos espaços itinerantes que "explica muitas das soluções que se passaram a por em prática dentro e fora das feiras" ( $p$. 46). Encontramos no capítulo a ideia de que os espaços têm memória; a variedade de espetáculos num mesmo espaço, segundo a autora, trazia um resíduo espectral nas salas e o diálogo estético era, por vezes, inevitável.

O livro enfatiza a história da sala de exibição, seu imobiliário e programações, como parte indissociável da história do cinema. Compreende ainda a rotina de ir ao cinema e a etiqueta que envolve esse hábito. Desse modo, o segundo capítulo destaca hábitos de espectatorialidade, como os dos frequentadores do cinema Tivoli, o mais elegante dentre os que existiam em Lisboa na década de 1920 (p. 78 e 79):

O acto de "ir ao Tivoli" fazia parte de uma certa vivência urbana que servia para ver quem lá estava e para ser visto também, definindo formas de convivialidade, com as quais se ocupava o espírito e a partir das quais se construía uma vida em sociedade, também ela em vias de transformação.

A autora convoca os poderes arquitetônicos do templo para sublinhar os rituais de espectatorialidade da época. Por isso a necessidade de passagens da imprensa bem compiladas, precisamente usadas ao longo do capítulo, com destaque para o texto de António Lopes Ribeiro, publicado na revista Imagem em maio de 1930, no qual se tenta definir o que é um espectador de cinema (p. 131): "o espectador é tão enigmático como o próprio espetáculo"; "para o espectador de cinema, gostar de um filme é ter chorado, ouvido, compreendido, ou não. Não gostar é o mesmo - e ainda mais".

A autora propõe três metáforas para as salas de cinema: o templo, a fábrica e o navio. No capítulo terceiro, vemos os desenvolvimentos das fachadas publicitárias 
no cinema Éden com grandes painéis pintados a mão. Analisa também a inauguração da Cinemateca Nacional, que ainda não funcionava nos termos que conhecemos hoje, o surgimento da figura do cinéfilo e da atividade cineclubista. $O$ culto ao cinema num nível de intimidade que dispensava os atrativos arquitetônicos das grandes salas. Assuntos que são levados para o quarto capítulo, que também explora a importância detalhada de cada grande sala da cidade.

O quinto (e talvez mais importante) capítulo traça um paralelo entre a ditatura de Salazar e uma atmosfera sufocante de cafés e cigarros. Segundo a autora, o surgimento dos cafés e snack-bares (lanchonetes) e a proximidade que mantinham com os cinemas definem novas rotinas na cidade, e, por consequência, novos territórios. Os cinemas se expandem para além do centro. Os cinemas de bairro, que não possuíam a mesma grandiosidade dos cinemas centrais, eram, no entanto, percebidos como um bem efetivo. Eram cinemas de reprise, com poltronas menos confortáveis, mas que gozavam de popularidade porque, argumenta a autora, se inseriam na rotina das pessoas que não precisavam mais se deslocar até o centro para assistir a um espetáculo. Se por um lado a tese principal do livro enfatiza a importância das grandes salas que, por vezes, distraíam o espectador não habituado com sua riqueza de detalhes, por outro, este capítulo reconhece a intimidade que se cria entre o público e o cinema de bairro. Para explicar esse fenômeno a autora recorre a um acontecimento mais geral e rotineiro, aproximando o hábito de frequentar cinemas da "relação com o espaço que é suscitada pela experiência da cidade" (p. 278). A cidade e a História se combinam na memória, "os lugares que a referenciam fundem-se com as histórias que neles se passam, e são integradas como marcas que thes dão vida e significado" (ibidem). Há uma espécie de resíduo que a história deixa nos lugares que, com os cinemas, se mistura aos filmes vistos:

De uma maneira geral, o espectador liga as salas aos filmes que nelas viu, e as emoções que estes desencadeiam entranham-se nesses espaços povoando-os como fantasmas. Talvez por isso se tivesse quase sempre a sensação de que não havia salas vazias. Nelas pareciam habitar espectros que conviviam com as imagens e os sons que os cineastas montavam e que se fundiam com o lugar numa presença única. Os cinemas concretizavam assim a relação que o espectador estabelecia com 
o universo dos filmes e com as suas emoções, condensando-as e engrandecendo-as ao mesmo tempo. Essa ligação aumentava, por seu lado, a envergadura dos edifícios, dignificando-os e integrando-os numa dinâmica de utilização que, muitas vezes não tinha correspondência directa com a qualidade das suas arquitecturas. (p. 279)

Portanto, ao mesmo tempo em que se detém sobre a importância de "átrios, corredores, foyers, alcatifas, cortinados de veludo que se abriam e fechavam junto do ecrã, uma certa iluminação, música nos intervalos, e o toque de um sino ou campainha que anunciava o início das sessões" (p. 277) nos grandes cinemas, a autora também reconhece a importância da sala e sua grandeza simbólica.

O último capítulo é dedicado ao desaparecimento das grandes e pequenas salas de rua, e a natural integração dos cinemas aos shopping centers em multissalas. Com um tom carregado de desalento, o capítulo apura a relação, agora desfeita, proposta durante o livro de "que os cinemas mantinham com o espaço público, o papel que desempenhavam na afirmação da cidade e na sinalização das ruas" (p. 318). Desde os anos 1980, uma série de fatores contribuiu para a queda do público, esbarrando na exigência por rentabilidade dos exibidores. Além disso, a autora aponta a ausência de um plano que contornasse a excessiva preocupação com a rentabilidade. Um a um, os cinemas - construídos pela leitura para estrangeiros - são demolidos, esvaziados, remodelados. Viram hotéis, mercados, escritórios. Nesse ponto, por mais que o livro seja ancorado a dados concretos, referentes aos cinemas da cidade, faz falta uma menção ao contexto mundial com o mesmo fenômeno ocorrendo ao redor do mundo.

Nas últimas páginas o discurso é derrotista sobre as condições tanto da cidade quanto do cinema. Com as reservas de que são "conclusões impressivas que podem ser refutadas", a autora lamenta que hoje são esvaziadas as palavras "cinema" e "espectador", assim como a "ida ao cinema" perdeu seu sentido, com os antigos rituais extintos. O lamento sustenta a tese presente no livro que une 0 cinema a um tipo específico de sala, e o espectador àquele que à frequenta. Cinema e espectador são conceitos que só existem em relação, um não se sustenta sem o outro. A autora, portanto, não reconhece as novas salas e os novos rituais de espectatorialidade como legítimos, na medida em que elege um 
tipo de espaço, a sala de cinema tradicional por suas particularidades arquitetônicas. Naturais são as conclusões de "fim do cinema", partindo de pressupostos assim.

Um trabalho que analisasse a grandeza arquitetônica dos espaços construídos através da tela, por mais exaustivo que fosse, muito provavelmente, não conseguiria abarcar todas as possibilidades apresentadas, como o livro tenta fazer com cada sala de Lisboa. Por outro lado, as metáforas de templo, fábrica e navio, que se remetem ao culto, maquinário e imaginação próprios ao cinema, são características que se mantém, à parte do desaparecimento da face do cinema no tecido urbano. Acciaiuoli não se aventura a estabelecer tais espaços, como fazem muitos livros de cinema. Sua análise é prioritariamente histórica e de arquitetura e, por isso, diversa; porém de singular importância para pesquisadores, somando mais uma voz aos estudos de história do cinema. Ainda que aponte para o seu fim. 